\title{
The Agulhas System and its role in changing ocean circulation, climate, and marine ecosystems
}

\section{Stellenbosch, Republic of South Africa, 8-12 October 2012}

\section{Rainer Zahn' ${ }^{1}$, W.P.M. de RuIJTER ${ }^{2}$, L. BeAL ${ }^{3}$, A. BIASTOCH ${ }^{4}$ AND SCOR/WCRP/IAPSO Working Group $136^{5}$}

'Institut de Ciència i Tecnologia Ambientals, Universitat Autònoma de Barcelona, Bellaterra, Spain; rainer.zahn@uab.cat ${ }^{2}$ Institute for Marine and Atmospheric Research, Utrecht University, The Netherlands; ${ }^{3}$ Rosenstiel School of Marine and Atmospheric Science, University of Miami, USA; ${ }^{4}$ GEOMAR Helmholtz Centre for Ocean Research, Kiel, Germany; ${ }^{5}$ www.scor-int.org/Working_Groups/wg136.htm

$T^{h}$ his conference was held in recognition of the significance of the Agulhas Current to ocean physical circulation, marine biology and ecology, and climate at the regional to global scale. The conference centered on the dynamics of the Agulhas Current in the present and the geological past; the influence of the current on weather, ecosystems, and fisheries; and the impact of the Agulhas Current on ocean circulation and climate with a notable focus on the Atlantic Meridional Overturning Circulation (AMOC). 108 participants from 20 countries, including seven African countries, attended the conference, of which a quarter were young researchers at the $\mathrm{PhD}$ student level. Participants came from the areas of ocean and climate modeling, physical and biological oceanography, marine ecology, paleoceanography, meteorology, and marine and terrestrial paleoclimatology. The Agulhas Current attracts interest from these communities because of its significance to a wide range of climatic, biological and societal issues.

The current sends waters from the Indian Ocean to the South Atlantic. This is thought to modulate convective activity in the North Atlantic. It is possible that it even stabilizes the AMOC at times of global warming when freshwater perturbation in the North might weaken it. But these feedbacks are not easy to trace, and direct observations and climate models have been the only way to indicate the possible existence of such far-field teleconnections to date. This is where marine paleo-proxy profiles prove helpful. They reveal the functioning of the Agulhas Current under a far larger array of climatic boundary conditions than those present during the short period of instrumental observations. For instance altered conditions in the past with shifted ocean circulation and wind fields stimulated Agulhas water transports from the Indian Ocean to the Atlantic, the so-called Agulhas leakage, at very different rates from today's. A number of the paleo-records that were shown at the meeting demonstrated a link between Agulhas leakage and Dansgaard/ Oeschger-type abrupt climate changes in the North Atlantic region, suggesting that salt-water leakage may have played a role in strengthening the AMOC and sudden climate warming in the North.

Marine ecosystems were also shown to be measurably impacted by the Agulhas system. Notably, the high variability associated with the prominence of mesoscale eddies and dipoles along

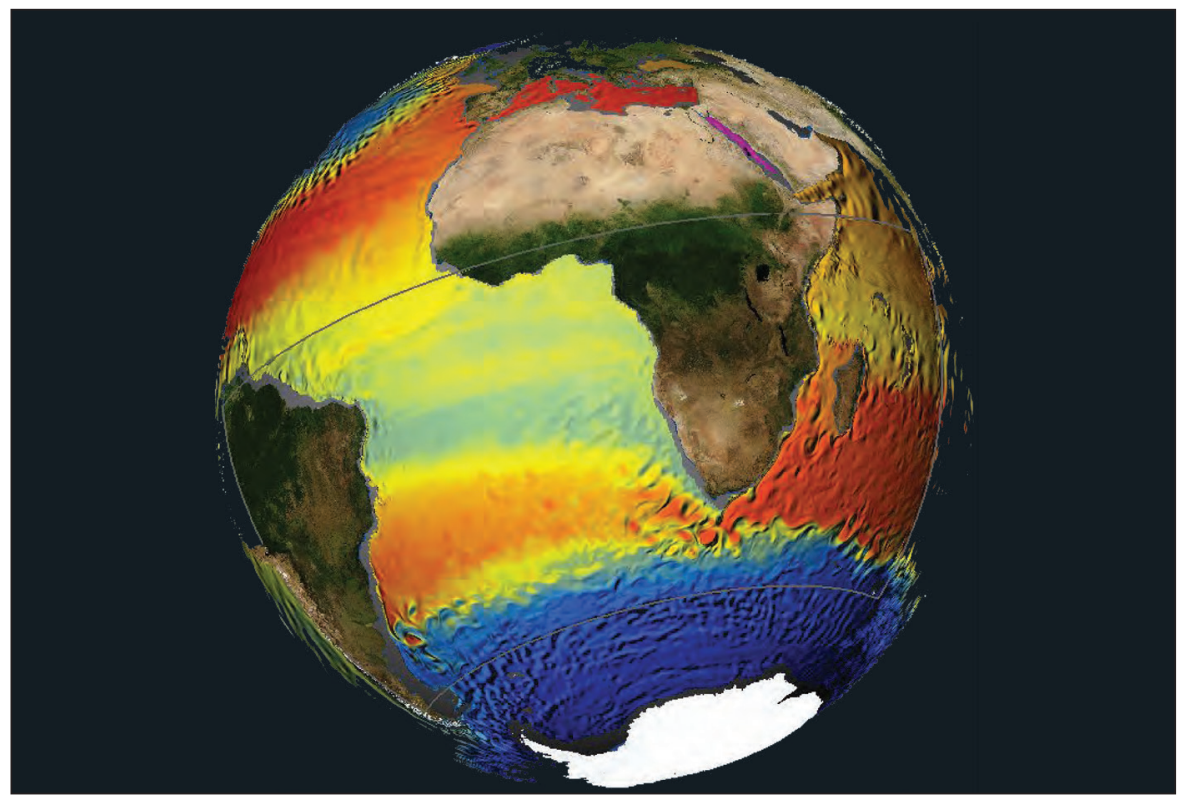

Figure 1: A model perspective of Agulhas leakage and the interbasin water transports between the Indian Ocean and Atlantic. A high-resolution Agulhas model $\left(1 / 10^{\circ}\right.$, gray box), is nested in a $\left(1 / 2^{\circ}\right)$ global ocean/sea ice model to simulate temperature and magnitude of currents (see Biastoch et al. 2009). the Current affect plankton communities, large predators, pelagic fish stocks, and possibly even facilitate the northward sardine runs swimming against the vigorous southward flow of the Agulhas Current.

The meteorological relevance of the Agulhas Current was also demonstrated, for example its role as a prominent source of atmospheric heat and its significance in maintaining and anchoring storm tracks. Among other things, these affect the atmospheric westerly Polar Front Jet and Mascarene High, with onward consequences for regional weather patterns, including extreme rainfall events over South Africa.

The conference developed a number of recommendations; two key ones being that efforts should be made to trace the impacts of the Agulhas leakage on the changing global climate system at a range of timescales, and that sustained observations of the Agulhas system should be developed. Implementing these recommendations would constitute a major challenge logistically and the Western Indian Ocean Sustainable Ecosystem Alliance (WIOSEA) was identified as a possible integrating platform for the cooperation of international and regional scientists toward these goals. This would involve capacity building and training regional technicians and scientists, which could be coordinated through partnerships with the National Research Foundation in South Africa.

The conference was held under the auspices of the American Geophysical Union Chapman Conference series and organized by the Scientific Committee on Oceanic Research (SCOR)/ World Climate Research Program (WCRP)/ International Association for the Physical Sciences of the Oceans (IAPSO) Working Group 136. Additional sponsorship came from the International Union of Geodesy and Geophysics; US NSF; NOAA; PAGES; Institute of Research for Development (IRD) France; and the Royal Netherlands Institute for Sea Research.

\section{References}

Biastoch A, Böning CW, Schwarzkopf FU, Lutjeharms JRE (2009) Nature 462: 495-499 